\title{
Breeding and Analysis of Two New Grapefruit-Like Varieties with Low Furanocoumarin Content
}

\author{
Lena Fidel ${ }^{1}$, Mira Carmeli-Weissberg1, Yosef Yaniv ${ }^{1}$, Felix Shaya ${ }^{1}$, Nir Dai ${ }^{1}$, Eran Raveh ${ }^{1}$, \\ Yoram Eyal' ${ }^{1}$, Ron Porat ${ }^{2}$, Nir Carmi ${ }^{*}$ \\ ${ }^{1}$ Institute of Plant Sciences, Bet Dagan, Israel \\ ${ }^{2}$ Institute of Postharvest and Food Sciences, Agricultural Research Organization, Volcani Center, \\ Bet Dagan, Israel \\ Email: "nircarmi@volcani.agri.gov.il
}

Received 28 December 2015; accepted 20 February 2016; published 23 February 2016

Copyright (C) 2016 by authors and Scientific Research Publishing Inc.

This work is licensed under the Creative Commons Attribution International License (CC BY). http://creativecommons.org/licenses/by/4.0/

(c) (i) Open Access

\section{Abstract}

Furanocoumarins (FCs) are a group of related plant defense metabolites occurring in several plant families, including some species in the genus citrus, such as grapefruit and pummelo. FCs function as toxins against pathogens, insects and other plant pests and some are toxic to humans at high levels. Although the levels of FCs in grapefruits are non-toxic to humans, they inhibit the intestinal enzyme CYP3A, thus preventing degradation of medicines, such as statins, and causing dangerous overdose effects. This overdosing can cause devastating side effects, ranging from stomach bleeding to kidney problems, muscle aches and irregular heartbeats. In the present study, we utilize LC/MS to characterize the levels of FCs pathway intermediates and end products in twelve citrus cultivars, including mandarin (Citrus reticulata), orange [Citrus sinensis (L.) Osbeck], Pummelo [Citrus maxima (Burm.) Merr.], grapefruit (Citrus paradisi Macf.), and two newly selected grapefruit like varieties [(Citrus reticulata) $\mathrm{X}$ [Citrus maxima (Burm.) Merr]. The orange and mandarin varieties do not contain FCs or FCs precursor compounds suggesting that this biosynthetic pathway is absent or inactive in mandarins and oranges and therefore a good genetic source for null alleles to FCs biosynthesis. We report the selection and characterization of two new low FCs and seedless grapefruit-like varieties, "Aliza" and "Coocki", developed by a cross between pummelo and mandarin. Fruits of these varieties resemble grapefruit and contain high levels of the flavanone naringin, typical of grapefruit, but contain only trace amounts of FCs (based on LC/MS analysis). Based on the variability of FCs content and inheritance in citrus species, the results suggest that future development of new low-FCs grapefruit varieties is an achievable objective.

\footnotetext{
${ }^{*}$ Corresponding author.
} 


\section{Keywords}

\section{Citrus, Grapefruit, Furanocoumarins, Breeding}

\section{Introduction}

Furanocoumarins (FCs) are plant defense compounds that function as toxins against pathogens, insects and other plant pests [1] [2]. Insects exposed to linear FCs suffer decreased larval weight, extended generation time and increased mortality [3]. High doses of some FCs are also toxic to humans; among maladies caused in humans by FCs are "celery picker's itch" and "bartender's itch", caused by contact with FCs-containing celery plants or oil of lime peels, respectively. Also, FCs can cause temporary or even permanent blindness if introduced into the eyes. Some FCs are also carcinogenic and teratogenic, i.e. they can cause cancer and birth defects, respectively [3]-[5].

FCs are found in several plant families, including edible plant species such as the citrus species pummelo and grapefruit, but the levels of mutagenic FCs (such as psoralen) in pummelo and grapefruits are rather low, and therefore there is no risk associated with consumption of their fruit and juice for healthy individuals [3]. Citrus is one of the most important fruit crops worldwide with total annual production of 115.5 million tons, to which grapefruit contributes about 5.5\% [6]. However, in recent years, there has been a decline in grapefruit consumption, especially in the US, as a result of the "grapefruit juice effect", attributed to FCs: FC-containing grapefruit juice negatively affects the body's degradation of medicines, including statins, leading to overdose effects.

The mechanism of the "grapefruit juice effect" is based on FCs that inhibit the intestinal drug catabolic enzyme CYP3A, thereby leading to accumulation of medicines, which in turn can lead to harmful effects ranging from relatively mild hypotension and dizziness in the case of some calcium-channel blockers, to potentially severe nephrotoxicity in the case of some immunosuppressant drugs [5] [7]-[16].

Drugs that interact with FCs [17] include:
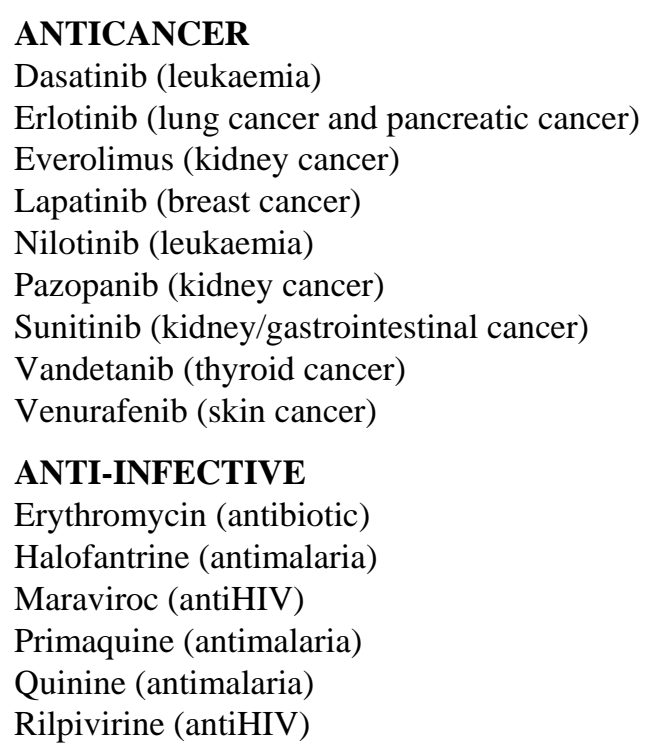

ANTICHOLESTEROL

Atorvastatin

Lovastatin

Simvastatin

CARDIOVASCULAR

Amiodarone (heart rhythm disorders)

Apixaban (anticlotting) 


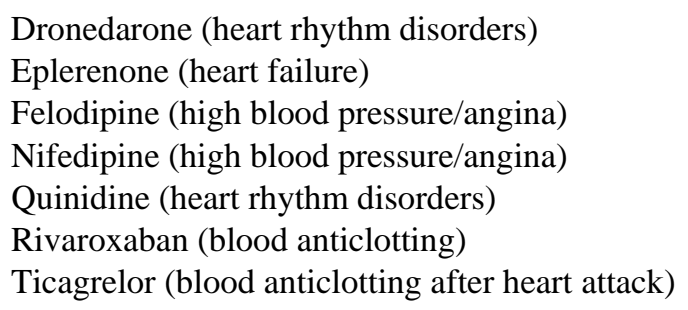

CENTRAL NERVOUS SYSTEM

Oral alfentanil (painkiller)

Oral fentanyl (painkiller)

Oral ketamine (painkiller, sedative)

Lurasidone (schizophrenia/mental health problems)

Oxycodone (painkiller)

Pimozide (schizophrenia/other mental health problems)

Ziprasidone (schizophrenia, mania, bipolar disorder)

\section{GASTROINTESTINAL}

Domperidone (antinausea)

\section{IMMUNOSUPPRESSANTS}

Cyclosporine (post organ transplant, rheumatoid arthritis, psoriasis)

Sirolimus (post organ transplant)

Tacrolimus (post organ transplant)

\section{URINARY TRACT}

Solifenacin (frequent urination/incontinence)

Silodosin (enlarged prostate)

Tamsulosin (enlarged prostate)

The FC-biosynthesis pathway starts with the amino acid phenylalanine (Figure 1) via umbelliferone to obtain linear or angular FCs. In citrus, only the linear FC-biosynthesis pathway is present which leads to formation of demethyl suberosin by alkylation of umbelliferone (Figure 1). Three FCs-6,7-dihydroxybergamottin (6,7DHB), bergamottin and paradisin C, appear to co-segregate genetically, which suggests that these three compounds are tightly linked metabolically as co-products of the "bergamottin pathway" [19]. Ranked in descending order of their inhibitory potency, the FCs found in grapefruit are: paradisin C > 6,7-DHB > bergamottin > isoimperatorin $>$ bergapten $>$ bergaptol [9] [20].

In the present study, we report on variations in the biosynthesis levels of various FCs in diverse varieties of grapefruit and pummelo. Twelve citrus cultivars (Table 1), including four pummelos, two grapefruits, one mandarin, one orange and three newly selected grapefruit-like varieties, were tested for juice and leaf levels of five furanocumarins (FCs) — bergamottin, bergaptol, epoxy bergamottin, 6,7-dihydroxybergamottin and isoimperatorin- and two FC precursors-psoralen and umbelliferone. The results show that the orange and the mandarin do not contain FCs; moreover, the lack of FC precursor compounds suggests that the biosynthesis pathway is entirely not active in mandarins and oranges. We also observe great diversity in the accumulation of FCs and their precursor compounds in various grapefruit and pummelo cultivars. Finally, we describe two new low-FC and seedless grapefruit-like cultivars, "Aliza" and "Cookie" that were selected in our breeding program by induced mutagenesis [21].

\section{Materials and Methods}

\subsection{Materials and Chemicals}

Bergamottin (purity $>99 \%$ ) was purchased from Fluka (Buchs, Switzerland); bergaptol (>99\%) and naringin (purity $>99 \%$ ) from Extrasynthese (Genay, France); epoxybergamottin (99\%), 6,7-DHB (99\%) and isoimperatorin (99\%) from Herboreal Ltd. (Dalkeith, United Kingdom); andpsoralen (>99\%) and umbelliferone (99\%); from Sigma-Aldrich (Steinem, Germany). 


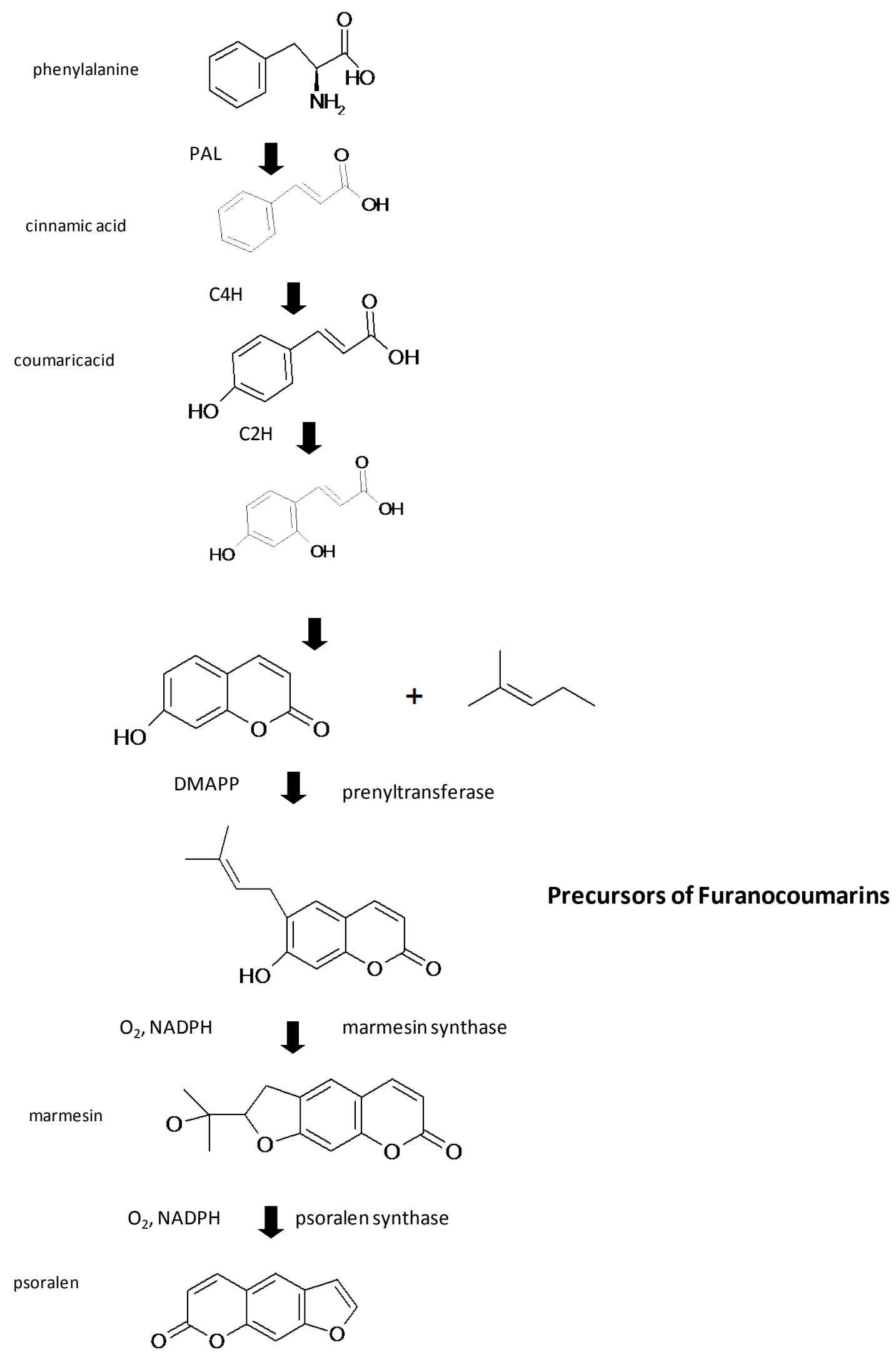




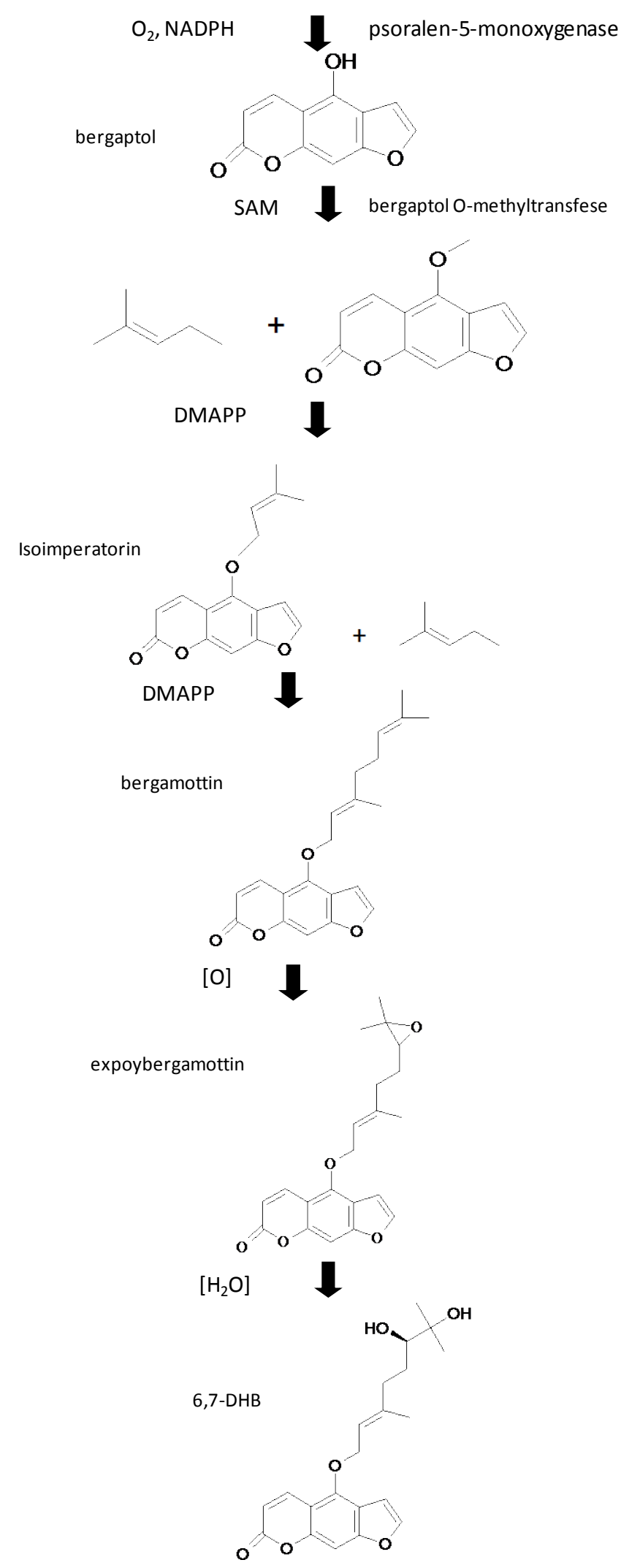

Furanocoumarins

Figure 1. The linear FC biosynthesis pathway from phenylalanine to 6,7-dihydroxybergamottin (6,7-DHB). The chemical structures were taken from the PubChem database [18]. 
Table 1. List of analyzed cultivars.

\begin{tabular}{|c|c|c|c|}
\hline Cultivar & Group & $\left(\jmath^{1}\right)$ & $(q)$ \\
\hline Tahitian & $\begin{array}{l}\text { Pummelo [Citrus maxima } \\
\text { (Burm.) Merr.] }\end{array}$ & ND & ND \\
\hline Chandler & $\begin{array}{l}\text { Pummelo [Citrus maxima } \\
\text { (Burm.) Merr.] }\end{array}$ & $\begin{array}{l}\text { "Siamese Pink” pummelo [Citrus } \\
\text { maxima (Burm.) Merr.] }\end{array}$ & $\begin{array}{l}\text { "Siamese Sweet” pummelo [Citrus maxima } \\
\text { (Burm.) Merr.] }\end{array}$ \\
\hline Marsh & $\begin{array}{l}\text { Grapefruit (Citrus paradisi } \\
\text { Macf.) }\end{array}$ & Orange [Citrus sinensis (L.) Osbeck] & Pummelo [Citrus maxima (Burm.) Merr.] \\
\hline Duncan & $\begin{array}{l}\text { Grapefruit (Citrus paradisi } \\
\text { Macf.) }\end{array}$ & Orange [Citrus sinensis (L.) Osbeck] & Pummelo [Citrus maxima (Burm.) Merr.] \\
\hline Valencia & $\begin{array}{l}\text { Orange [Citrus sinensis (L.) } \\
\text { Osbeck] }\end{array}$ & Citrus reticulata & Pummelo [Citrus maxima (Burm.) Merr.] \\
\hline Orah & Mandarin (Citrus reticulata) & "Temple" $(C$. reticulate $\times$ C. sinensis $)$ & $\begin{array}{l}\text { "Kinnow” mandarin(Citrus reticulata } \\
\text { Blanco) }\end{array}$ \\
\hline Flamingo & $\begin{array}{l}\text { Pummelo [Citrus maxima } \\
\text { (Burm.) Merr.] }\end{array}$ & $\begin{array}{l}\text { “Chandler” pummelo [Citrus maxima } \\
\text { (Burm.) Merr.] }\end{array}$ & $\begin{array}{l}\text { "Tahitian" pummelo [Citrus } \\
\text { maxima (Burm.) Merr.] }\end{array}$ \\
\hline Hanna & $\begin{array}{l}\text { Pummelo [Citrus maxima } \\
\text { (Burm.) Merr.] }\end{array}$ & $\begin{array}{l}\text { “Chandler” pummelo [Citrus maxima } \\
\text { (Burm.) Merr.] }\end{array}$ & $\begin{array}{l}\text { “Tahitian” pummelo } \\
\text { [Citrusmaxima (Burm.) Merr.] }\end{array}$ \\
\hline Einat & $\begin{array}{l}\text { A red triploid “Oroblanco”-like } \\
\text { citrusfruit }\end{array}$ & $\begin{array}{l}\text { Tetraploid "Hudson” (Citrus paradisi } \\
\text { Macf.) }\end{array}$ & $\begin{array}{l}\text { Acid-freepummelo [Citrus maxima (Burm.) } \\
\text { Merr.] }\end{array}$ \\
\hline Aliza & Grapefruit-like & $\begin{array}{l}\text { “Orah” mandarin (Citrus reticulata } \\
\text { Blanco) }\end{array}$ & $\begin{array}{l}\text { “Chandler” pummelo [Citrus maxima } \\
\text { (Burm.) Merr.] }\end{array}$ \\
\hline Dany & Grapefruit-like & $\begin{array}{l}\text { "Michal” mandarin (Citrus reticulata } \\
\text { Blanco) }\end{array}$ & $\begin{array}{l}\text { "Duncan” grapefruit (Citrus paradisi } \\
\text { Macf.) }\end{array}$ \\
\hline $\begin{array}{l}\text { Cookie } \\
\text { (seedless mandelo) }\end{array}$ & Grapefruit-like & “Frua” mandarin (Citrus reticulata) & $\begin{array}{l}\text { “Siamese Sweet” pummelo [Citrusmaxima } \\
\text { (Burm.) Merr.] }\end{array}$ \\
\hline
\end{tabular}

ND = not determined.

\subsection{Extraction of Furanocoumarins}

FCs were extracted from fruit juice and leaves. For the juice analysis, $10 \mathrm{ml}$ of juice of each cultivar were mixed with an equal volume of ethyl acetate. For the leaf analysis, $10 \mathrm{~g}$ of leaf tissue were ground in liquid nitrogen and mixed with ethyl acetate at a volume equivalent to the weight, i.e. $10 \mathrm{ml}$. The extraction was performed by vortex mixing for $5 \mathrm{~min}$ at $25^{\circ} \mathrm{C}$ followed by centrifugation at $3220 \mathrm{~g}$ for $25 \mathrm{~min}$ at $25^{\circ} \mathrm{C}$. The organic phase was collected and re-extracted with an equivalent volume of double-distilled water. The mixture was then remixed and centrifuged as described above. A 2-ml aliquot of the organic phase was evaporated under air flow and dissolved in $1 \mathrm{ml}$ of acetonitrile for LC-MS analysis.

\subsection{Extraction of Naringin}

The fruit slices were blended in a blender for $1 \mathrm{~min}$ and the blended material was mixed with butanol (1:1; v/v), centrifuged at $4^{\circ} \mathrm{C}$ at $10,000 \mathrm{~g}$ for $15 \mathrm{~min}$, and the butanol fraction was centrifuged again at $10,000 \mathrm{~g}$ for $10 \mathrm{~min}$. A 3-ml aliquot of the upper phase was dried in a speed-vacuum centrifuge, and the precipitate was dissolved in 5 $\mathrm{ml}$ of $100 \%$ methanol and filtered through a $0.45-\mu \mathrm{m}$ filter. LC-MS analyses were conducted with a UPLCTriple Quadrupole-MS (Waters Xevo TQ MS). The samples were again filtered, through a 0.22- $\mu \mathrm{m}$ Millex-HV Durapore (PVDF) membrane, before injection into the LC-MS apparatus. Separation was performed on $2.1 \times 50$ mm i.d., $1.7 \mu \mathrm{m}$ UPLC BEH C18 column. Chromatographic and MS parameters were as follows. The mobile phase consisted of water (phase A) and 0.1\% formic acid in acetonitrile (phase B). The linear-gradient programme was as follows: $100 \%$ to $95 \%$ A over $0.1 \mathrm{~min}, 95 \%$ to $5 \%$ A over 5 min, held at 5\% A for 2 min, then back to the initial conditions (95\% A) for $3 \mathrm{~min}$. The flow rate was $0.3 \mathrm{ml} \cdot \mathrm{min}^{-1}$ and the column temperature was kept at $35^{\circ} \mathrm{C}$. All of the analyses were performed with the ESI source in positive-ion mode, with a capillary voltage of $3.2 \mathrm{kV}$, a cone voltage of $30 \mathrm{~V}$, a desolvation temperature of $350^{\circ} \mathrm{C}$, a desolvation gas flow rate of 
$850 \mathrm{~L} / \mathrm{h}$ anda source temperature of $150^{\circ} \mathrm{C}$. Quantization was performed with MRM acquisition by monitoring the 581/152, 581/273 transitions, RT = 6.07, (dwell time of $161 \mathrm{~ms}$ for each transition) for naringin.

\subsection{LC-MS Analyses}

LC-MS analyses were conducted with a UPLC-Triple Quadrupole-MS (Waters Xevo TQ MS. Samples were filtered through a 0.22- $\mu$ m Millex-HV Durapore (PVDF) membrane before injection into the LC-MS apparatus. Separation was performed with a $2.1 \mathrm{~m} \times 50 \mathrm{~mm}$ i.d., $1.7 \mu \mathrm{m}$ UPLC BEH C18 column. Chromatographic and MS parameters were as follows. The mobile phase consisted of water (phase A) and $0.1 \%$ formic acid in acetonitrile (phase B). The linear-gradient programme for bergamottin, epoxy bergamottin, 6,7-dihydroxybergamottin, bergaptol and isoimperatorin was as follows: $100 \%$ to $95 \%$ A over $0.1 \mathrm{~min}, 95 \%$ to $5 \%$ A over 8 min, held at 5\% A for3 min, then back to the initial conditions (95\% A) for $3 \mathrm{~min}$. The linear-gradient programme for psoralen and umbelliferone was as follows: $100 \%$ to $95 \%$ A over $0.1 \mathrm{~min}, 95 \%$ to $5 \%$ A over $4 \mathrm{~min}$, held at $5 \%$ A for $3 \mathrm{~min}$, then back to the initial conditions (95\% A) for $3 \mathrm{~min}$. The flow rate was $0.3 \mathrm{ml} \cdot \mathrm{min}^{-1}$ and the column temperature was kept at $35^{\circ} \mathrm{C}$. All of the analyses were performed with the ESI source usedin positive-ion mode, with a capillary voltage of $3.2 \mathrm{kV}$, a cone voltage of $30 \mathrm{~V}$, a desolvation temperature of $350^{\circ} \mathrm{C}$, a desolvation gas flow of $650 \mathrm{~L} / \mathrm{h}$ and a source temperature of $150^{\circ} \mathrm{C}$. Quantitation was performed with MRM acquisition by monitoring the following transitions 339/147, 339/203 (RT = 7.1, dwell time of $161 \mathrm{~ms}$ ) for bergamottin; 355/153, 355/203 (RT = 5.6, dwell time of $78 \mathrm{~ms}$ ) for epoxy bergamottin; 373/153, 373/203 (RT = 4.2, dwell time of 78 ms) for 6,7-DHB; 202/131, 202/146 (RT = 3.1, dwell time of $161 \mathrm{~ms}$ ) for bergaptol; 271/146, $271 / 203$ (RT = 5.5, dwell time of $161 \mathrm{~ms}$ ) for isoimperatorin; 187/115, 187/13 (RT = 2.46, dwell time of $78 \mathrm{~ms})$ for psoralen and $163 / 91,163 / 107$ (RT = 1.8, dwell time of $78 \mathrm{~ms}$ ) for umbelliferone.

\subsection{Statistical Analysis}

One-way ANOVA and Turkey’s HSD pair-wise comparison tests were applied by means of JMP statistical software, version 7 (SAS Institute Inc., Cary, NC, USA) and Microsoft’s Office Excel.

\section{Results and Discussion}

FCs were found at varied concentrations in different cultivars, but were completely absent from mandarins, oranges and were close to absent in the new grapefruit-like varieties “Aliza” and "Cookie” (Figure 2). In grapefruit and pummelo, Bergamottin and 6,7-DHB were found at higher concentrations than other FCs, probably because they are final products that accumulate over time. In correlation, the FC precursors are present in very low concentrations in grapefruit and pummelo (Figure 2), as they are utilized for biosynthesis of the final products. Interestingly, although the FC biosynthesis pathway of grapefruit (Figure 1) was inherited from pummelo, the accumulated concentrations of bergamottin and 6,7-DHB in the grapefruit cultivars "Duncan" and "Marsh" (a seedless mutation of "Duncan”) were much higher than those observed in the pummelo cultivars that we examined (Figure 2).

The complete absence of FCs and FC precursors, from umbelliferone to psoralen in oranges and mandarins (Figure 2), suggests that the entire pathway for biosynthesis of FC is absent or inactive in these species, and that only a null allele for FC biosynthesis can be inherited from these species. The new selection "Aliza”, a hybrid of "Chandler" pummelo and "Orah" mandarin is almost completely void of FCs, suggesting the pummelo parent is heterozygous for FC biosynthesis (i.e. contains one active copy and one inactive copy, presumably inherited by “Aliza”). Furthermore, the finding that the pummelo hybrid "Hana” (cross between "Chandler" and "Tahitian” pummelos) has no FCs (Figure 2) indicates that "Chandler” probably also contributed its inactive allele for FC biosynthesis to "Hana". In contrast, "Chandler" contributed its active allele for FC biosynthesis to the pummelo "Flamingo" (a different cross between "Chandler” and "Tahitian” pummelos) (Figure 2); the rather higher level of 6,7-DHB in "Flamingo" might be a result of the "release" of the isoimperatorin that accumulates in "Tahitian", by the active allele of "Chandler".

The concentrations of bergamottin and 6,7-DHB observed in 4- to 5-month-old leaves were extremely low relative to those observed in the fruits. Pummelo cultivars have much lower concentrations of epoxy bergamottin in their fruits versus other FCs compounds (Figure 2(a)), but the accumulated amounts of this FC in their leaves were equivalent to the highest concentrations observed among all of the examined cultivars (Figure 2). We note that, during commercial processing, epoxy bergamottin may be hydrolyzed to 6,7-DHB, which has been identi- 
(a)
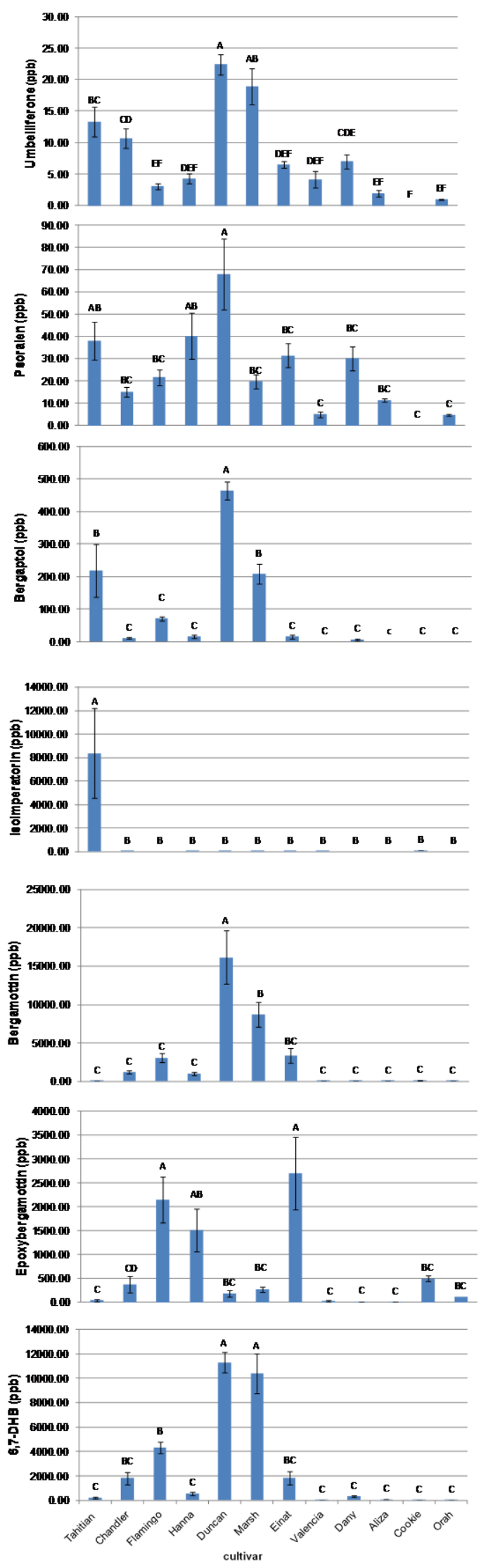
(b)
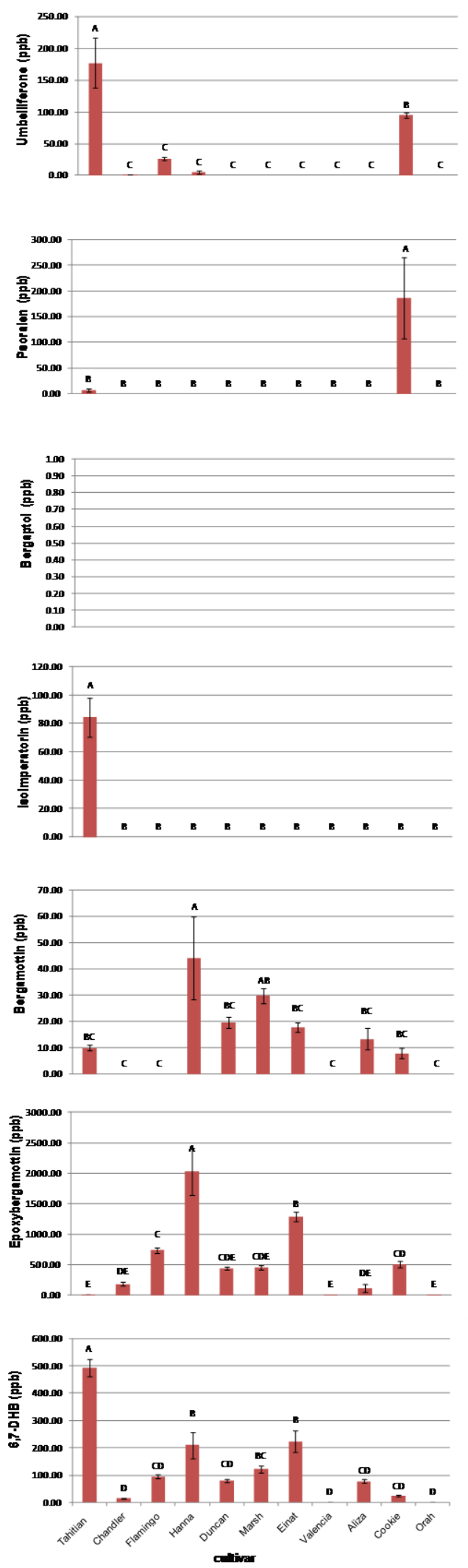

Figure 2. Analysis of FC levels in 12 citrus cultivars. FCs were analyzed in fruit (a) and leaf (b) tissues. Data are means of 3 replications. Different letters above columns indicate significant differences at $p \leq 0.05$. 
fied as a potentially important inhibitor of CYP3A4 [17] [22].

In all of the fruit juices of the examined cultivars, bergaptol and isoimperatorin were found at significantly lower concentrations than the other FCs, reflecting the fact that they are intermediate products in the pathway. However, pummelo "Tahitian" contained an extraordinarily high concentration of isoimperatorin; this pummelo also had very low concentrations of bergamottin and 6,7-DHB, suggesting that the pathway in this variety is partially blocked and it accumulates isoimperatorin instead of bergamottin and 6,7-DHB.

We have selected two new seedless grapefruit-like cultivars, "Aliza" and "Cookie" (Table 1), which do not accumulate FCs. At the start of ripening "Aliza" fruits have green skin and yellow flesh, but the former turns yellow later in the season, and when fully ripe these fruits have orange skin and orange flesh (Figure 3). By inducing mutations, we selected seedless types of "Aliza" and "Cookie" (Figure 3 and Figure 4). Both of these selections have unique and favorable characteristics: they are juicy and, because they contain naringin (Table 2), they have been classified as grapefruit-like cultivars; “Aliza” and "Cookie” are also easy to peel.

\section{Conclusion}

FC composition and concentrations are highly variable in citrus, suggesting that selection for new grapefruit like cultivars with low FCs is a feasible objective. Indeed, we describe the selection of two new low FC grapefruit-like varieties that are potentially safe for consumption by humans using statins and other drugs. The corre-

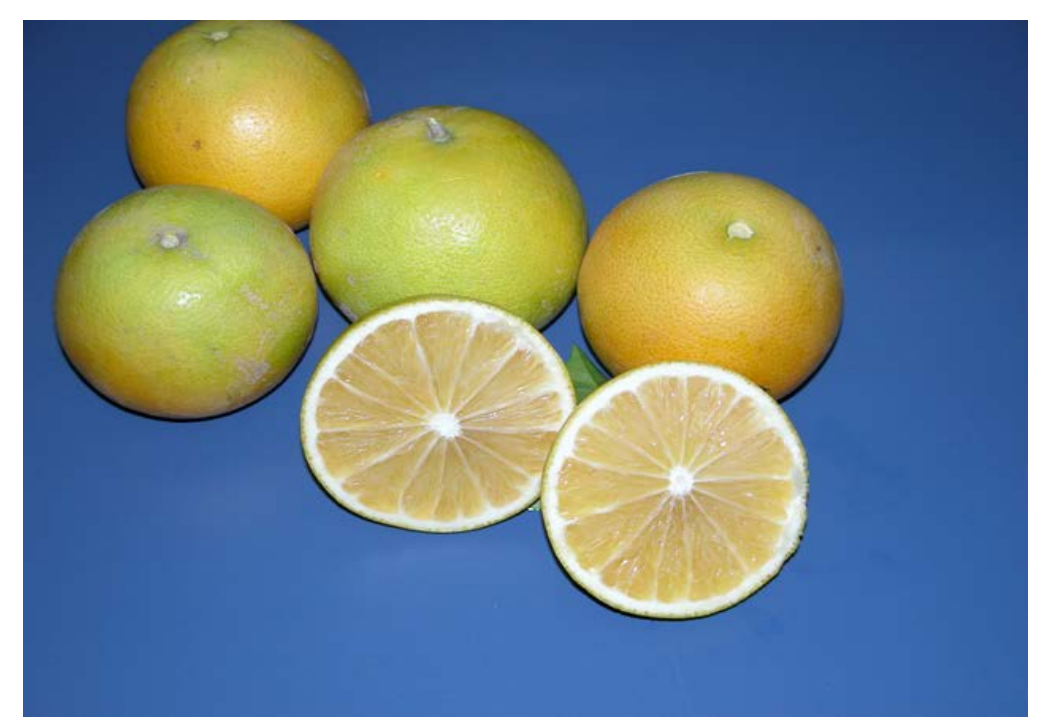

(a)

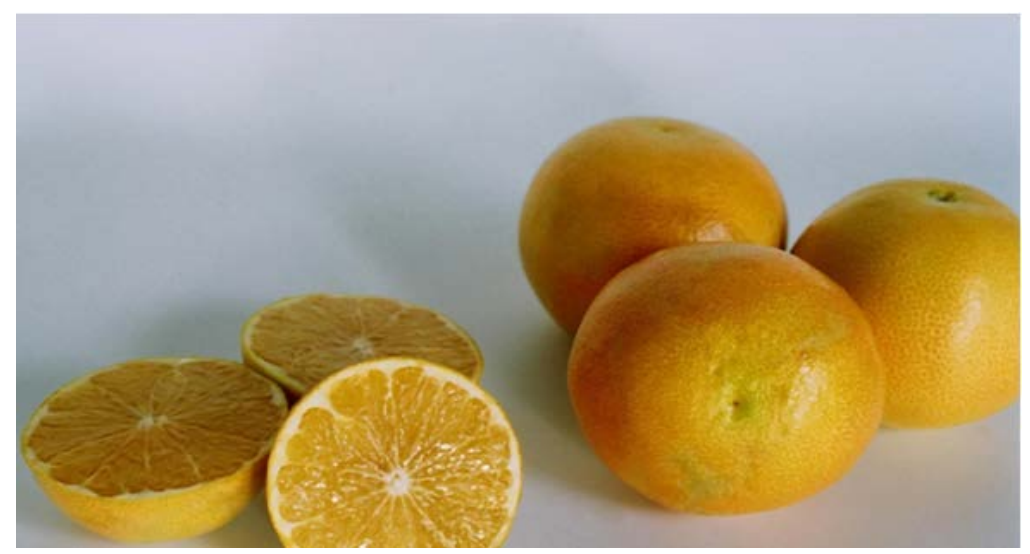

(b)

Figure 3. Photographs of "Aliza”, a new grapefruit-like cultivar, taken in November (a) and February (b). 

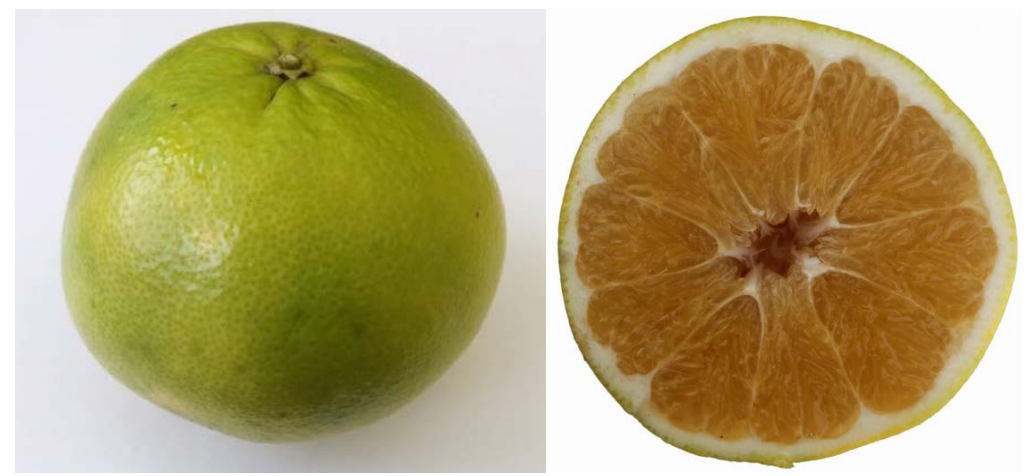

Figure 4. Photographs of "Cookie”, a new grapefruit-like cultivar.

Table 2. Quality traits and naringin contents in juices of 12 different citrus cultivars. Data are means \pm S.E. of 3 replications.

\begin{tabular}{|c|c|c|c|c|c|c|c|}
\hline Cultivar & $\begin{array}{c}\text { Seeds } \\
\text { (no. } \pm \text { SE) }\end{array}$ & $\begin{array}{c}\text { Sugar } \\
(\mathrm{Bx} \pm \mathrm{SE})\end{array}$ & $\begin{array}{c}\text { Acid } \\
(\% \pm \mathrm{SE})\end{array}$ & $\begin{array}{c}\text { Juice } \\
(\% \pm \mathrm{SE})\end{array}$ & $\begin{array}{c}\text { Size } \\
(\mathrm{g} \pm \mathrm{SE})\end{array}$ & $\begin{array}{l}\text { Naringin } \\
(\mathrm{ppb} \pm \mathrm{SE})\end{array}$ & $\begin{array}{l}\text { Ripening } \\
\text { season }\end{array}$ \\
\hline Tahitian & $\begin{array}{l}120.00 \\
( \pm 6.00)\end{array}$ & $\begin{array}{c}12.00 \\
( \pm 0.07)\end{array}$ & $\begin{array}{c}1.50 \\
( \pm 0.04)\end{array}$ & $\begin{array}{c}30.50 \\
( \pm 2.50)\end{array}$ & $\begin{array}{c}542.00 \\
( \pm 28.00)\end{array}$ & $\begin{array}{c}66690.56 \text { (B) } \\
( \pm 3072.85)\end{array}$ & October-November \\
\hline Chandler & $\begin{array}{c}84.00 \\
( \pm 6.00)\end{array}$ & $\begin{array}{l}12.00 \\
( \pm 0.04)\end{array}$ & $\begin{array}{c}0.80 \\
( \pm 0.02)\end{array}$ & $\begin{array}{c}9.00 \\
( \pm 0.80)\end{array}$ & $\begin{array}{c}684.00 \\
( \pm 34.00)\end{array}$ & $\begin{array}{c}144550.72(\mathrm{~A}) \\
( \pm 6871.74)\end{array}$ & October-November \\
\hline Flamingo & $\begin{array}{c}0.30 \\
( \pm 0.20)\end{array}$ & $\begin{array}{c}10.70 \\
( \pm 0.10)\end{array}$ & $\begin{array}{c}0.90 \\
( \pm 0.5)\end{array}$ & $\begin{array}{c}19.10 \\
( \pm 1.50)\end{array}$ & $\begin{array}{l}1218.00 \\
( \pm 60.00)\end{array}$ & $\begin{array}{c}75495.57 \text { (B) } \\
( \pm 4382.96)\end{array}$ & November-January \\
\hline Hanna & $\begin{array}{c}26.00 \\
( \pm 4.00)\end{array}$ & $\begin{array}{c}9.50 \\
( \pm 0.23)\end{array}$ & $\begin{array}{c}0.60 \\
( \pm 0.07)\end{array}$ & $\begin{array}{c}23.80 \\
( \pm 1.50)\end{array}$ & $\begin{array}{c}917.00 \\
( \pm 147.00)\end{array}$ & $\begin{array}{c}86314.11(\mathrm{~B}) \\
( \pm 11235.48)\end{array}$ & November-February \\
\hline Duncan & $\begin{array}{c}55.00 \\
( \pm 5)\end{array}$ & $\begin{array}{c}11.80 \\
( \pm 0.15)\end{array}$ & $\begin{array}{c}2.30 \\
( \pm 0.04)\end{array}$ & $\begin{array}{c}33.80 \\
( \pm 0.90)\end{array}$ & $\begin{array}{c}339.00 \\
( \pm 16.00)\end{array}$ & $\begin{array}{c}88589.18 \text { (B) } \\
( \pm 12461.56)\end{array}$ & October-April \\
\hline Marsh & $\begin{array}{c}3.00 \\
( \pm 1.00)\end{array}$ & $\begin{array}{c}11.20 \\
( \pm 0.12)\end{array}$ & $\begin{array}{c}2.00 \\
( \pm 0.04)\end{array}$ & $\begin{array}{c}35.60 \\
( \pm 1.10)\end{array}$ & $\begin{array}{l}372.00 \\
( \pm 9.00)\end{array}$ & $\begin{array}{c}42496.21(\mathrm{C}) \\
( \pm 3789.91)\end{array}$ & October-April \\
\hline Einat & $\begin{array}{c}2.70 \\
( \pm 1.30)\end{array}$ & $\begin{array}{c}9.50 \\
( \pm 0.3)\end{array}$ & $\begin{array}{c}1.80 \\
( \pm 0.05)\end{array}$ & $\begin{array}{c}23.70 \\
( \pm 1.10)\end{array}$ & $\begin{array}{c}687.00 \\
( \pm 30.00)\end{array}$ & $\begin{array}{c}67598.29 \text { (B) } \\
( \pm 5105.92)\end{array}$ & November-February \\
\hline Valencia & $\begin{array}{c}4.00 \\
( \pm 0.70)\end{array}$ & $\begin{array}{c}9.60 \\
( \pm 0.25)\end{array}$ & $\begin{array}{c}1.40 \\
( \pm 0.05)\end{array}$ & $\begin{array}{c}45.90 \\
( \pm 0.80)\end{array}$ & $\begin{array}{c}263.00 \\
( \pm 8)\end{array}$ & $\begin{array}{l}0.00(\mathrm{E}) \\
( \pm 0.00)\end{array}$ & February-May \\
\hline Dany & $\begin{array}{c}9.00 \\
( \pm 1.40)\end{array}$ & $\begin{array}{c}11.00 \\
( \pm 0.09)\end{array}$ & $\begin{array}{c}1.70 \\
( \pm 0.06)\end{array}$ & $\begin{array}{l}22.10 \\
( \pm 1.40)\end{array}$ & $\begin{array}{c}458.00 \\
( \pm 21.00)\end{array}$ & $\begin{array}{l}0.00(\mathrm{E}) \\
( \pm 0.00)\end{array}$ & January \\
\hline Aliza & 0.00 & $\begin{array}{c}10.40 \\
( \pm 0.20)\end{array}$ & $\begin{array}{c}0.70 \\
( \pm 0.03)\end{array}$ & $\begin{array}{c}42.80 \\
( \pm 1.60)\end{array}$ & $\begin{array}{c}621.00 \\
( \pm 58.00)\end{array}$ & $\begin{array}{c}31124.00 \text { (CD) } \\
\quad( \pm 3000.33)\end{array}$ & November-February \\
\hline Cookie & 0.00 & $\begin{array}{c}11.00 \\
( \pm 0.20)\end{array}$ & $\begin{array}{c}0.50 \\
( \pm 0.04)\end{array}$ & $\begin{array}{c}38.50 \\
( \pm 2.00)\end{array}$ & $\begin{array}{c}486.00 \\
( \pm 25.00)\end{array}$ & $\begin{array}{l}13865.00(\mathrm{DE}) \\
( \pm 1839.04)\end{array}$ & October- November \\
\hline Orah & $\begin{array}{c}16.00 \\
( \pm 1.60)\end{array}$ & $\begin{array}{c}12.10 \\
( \pm 0.18)\end{array}$ & $\begin{array}{c}1.10 \\
( \pm 0.04)\end{array}$ & $\begin{array}{c}35.70 \\
( \pm 1.10)\end{array}$ & $\begin{array}{l}155.00 \\
( \pm 5.00)\end{array}$ & $\begin{array}{l}0.00(\mathrm{E}) \\
( \pm 0.00)\end{array}$ & January-March \\
\hline
\end{tabular}

lation of FC accumulation between leaves and fruits provides a potential marker for screening young plantlets for additional FC-free grapefruit-like varieties.

\section{References}

[1] Berenbaum, M.R. (2003) Characterization of Furanocoumarin Metabolites in Parsnip Webworm, Depressaria pastinacella. Journal of Chemical Ecology, 29, 671-682. http://dx.doi.org/10.1023/A:1022872704016

[2] Widmer, W. (2006) One Tangerine/Grapefruit Hybrid (Tangelo) Contains Trace Amounts of Furanocoumarins at a Level Too Low to Be Associated with Grapefruit/Drug Interactions. Journal of Food Science, 70, 419-422. http://dx.doi.org/10.1111/j.1365-2621.2005.tb11440.x

[3] Diawara, M.M., Trumble, JT., White, K.K., Carson, W.G. and Martinez, L.A. (1993) Toxicity of Linear Furanocoumarins to Spodoptera exigua: Evidence for Antagonistic Interactions. Journal of Chemical Ecology, 19, 2473-2484. 
http://dx.doi.org/10.1007/BF00980684

[4] Pan, L., Wen, Z., Baudry, J., Berenbaum, M.R. and Schuler, M.A. (2004) Identification of Variable Amino Acids in the SRS1 Region of CYP6B1 Modulating Furanocoumarin Metabolism. Archives of Biochemistry and Biophysics, 422, 31-41. http://dx.doi.org/10.1016/j.abb.2003.09.047

[5] Gou, L.Q., Fukuda, K., Ohta, T. and Yamazoe, Y. (2000) Role of Furanocoumarin Derivatives in Grapefruit JuiceMediated Inhibition of Human CYP3A Activity. Drug Metabolism and Disposition, 28, 766-771.

[6] US Department of Agriculture (USDA-FAO) (2014) Citrus: World Markets and Trade. 1-9. http://apps.fas.usda.gov/psdonline/circulars/citrus.pdf

[7] Bailey, D.G., Malcolm, J., Arnold, O. and Spence, J.D. (1998) Grapefruit Juice-Drug Interactions. British Journal of Clinical Pharmacology, 46, 101-110. http://dx.doi.org/10.1046/j.1365-2125.1998.00764.X

[8] Bailey, D.G., Malcolm, J., Arnold, O. and Spence, J.D. (2004) Grapefruit Juice-Drug Interactions. British Journal of Clinical Pharmacolog, 58, S831-S843. http://dx.doi.org/10.1111/j.1365-2125.2004.02305.X

[9] Ohnishi, A., Matsuo, H., Yamada, S., Takanaga, H., Morimoto, S., Shoyama, Y., Ohtani, H. and Sawada, Y. (2000) Effect of Furanocoumarin Derivatives in Grapefruit Juice on the Uptake of Vinblastine by Caco-2 Cells and on the Activity of Cytochrome P450 3A4. British Journal of Pharmacology, 130, 1369-1377. http://dx.doi.org/10.1038/sj.bjp.0703433

[10] Wen, Y.H., Sahi, J., Urda, E., Kulkarni, S., Rose, K., Zheng, X., Sinclair, J.F., Cai, H., Strom, S.C. and Kostrubsky, V.E. (2002) Effects of Bergamottin on Human and Monkey Drug-Metabolizing Enzymes in Primary Cultured Hepatocytes. Drug Metabolism and Disposition, 30, 977-984. http://dx.doi.org/10.1124/dmd.30.9.977

[11] Widmer, W. and Haun, C. (2005) Variation in Furanocoumarin Content and New Furanocoumarin Dimers in Commercial Grapefruit (Citrus paradisi Macf.) Juices. Journal of Food Science, 70, C307-C312. http://dx.doi.org/10.1111/j.1365-2621.2005.tb07178.x

[12] Paine, M.F., Criss, A.B. and Watkins, P.B. (2005) Two Major Grapefruit Juice Components Differ in Time to Onset of Intestinal CYP3A4 Inhibition. Journal of Pharmacology and Experimental Therapeutics, 312, 1151-1160. http://dx.doi.org/10.1124/jpet.104.076836

[13] Paine, M.F., Widmer, W.W., Hart, H.L., Pusek, S.N., Beavers, K.L., Criss, A.B., Brown, S.S., Thomas, B.F. and Watkins, P.B. (2006) A Furanocoumarin-Free Grapefruit Juice Establishes Furanocoumarins as the Mediators of the Grapefruit Juice-Felodipine Interaction. The American Journal of Clinical Nutrition, 83, 1097-1105.

[14] De Castro, W.V., Mertens-Talcott, S., Rubner, A., Butterweck, V. and Derendorf, H. (2006) Inhibitory Effect on Monooxygenases Involved in Drug Metabolism and Potential Toxicity. Journal of Agricultural and Food Chemistry, 54, 249-255. http://dx.doi.org/10.1021/jf0516944

[15] Dugrand, A., Olry, A., Duval, T., Hehn, A., Froelicher, Y. and Bourgaud, F., (2013) Coumarin and Furanocoumarin Quantitation in Citrus Peel via Ultraperformance Liquid Chromatography Coupled with Mass Spectrometry (UPLCMS). Journal of Agricultural and Food Chemistry, 61, 10677-10684. http://dx.doi.org/10.1021/jf402763t

[16] VanderMolen, K.M., Ainslie, G.R., Paine, M.F. and Oberlies, N.H. (2014) Labeled Content of Two Furanocoumarins in Dietary Supplements Correlates with neither Actual Content nor CYP3A Inhibitory Activity. Journal of Pharmaceutical and Biomedical Analysis, 98, 260-265. http://dx.doi.org/10.1016/j.jpba.2014.05.038

[17] Bailey, D.G., Dresser, G. and Arnold, J.M. (2013) Grapefruit-Medication Interactions: Forbidden Fruit or Avoidable Consequences? CMAJ, 185, 309-316. http://dx.doi.org/10.1503/cmaj.120951

[18] Wang, Y., Xiao, J., Suzek, T.O., Zhang, J., Wang, J. and Bryant, S.H. (2009) PubChem: A Public Information System for Analyzing Bioactivities of Small Molecules. Nucleic Acids Research, 37, W623-W633. http://dx.doi.org/10.1093/nar/gkp456

[19] Chen, C., Cancalon, P., Haun, C. and Gmitter Jr., F. (2011) Characterization of Furanocoumarin Profile and Inheritance toward Selection of Low-Furanocoumarin Seedless Grapefruit Cultivars. Journal of the American Society for Horticultural Science, 136, 358-363.

[20] Row, E.C., Brown, S.A., Staculski, A.V. and Lennard, M.S. (2006) Design, Synthesis and Evaluation of Furanocoumarin Monomers as Inhibitors of CYP3A4. Organic \& Biomolecular Chemistry, 4, 1604-1610. http://dx.doi.org/10.1039/b601096b

[21] Vardi, A., Levin, I. and Carmi, N. (2008) Induction of Seedlesness in Citrus: From Classical to Emerging Biotechnological Approaches. Journal of the American Society for Horticultural Science, 133, 117-126.

[22] Wangensteen, H., Molden, E., Christensen, H. and Malterud, K. (2003) Identification of Epoxybergamottin as a CYP3A4 Inhibitor in Grapefruit Peel. European Journal of Clinical Pharmacology, 58, 663-668. 